\title{
Evaluation of corneal symmetry after UV corneal crosslinking for keratoconus
}

\author{
This article was published in the following Dove Press journal: \\ Clinical Ophthalmology \\ Number of times this article has been viewed
}

\author{
Hanan Mofty ${ }^{1,2}$ \\ Khaled Alzahrani ${ }^{2}$ \\ Fiona Carley ${ }^{3}$ \\ Sophie Harper ${ }^{3}$ \\ Arun Brahma ${ }^{3}$ \\ Leon $\mathrm{Au}^{3}$ \\ Debbie Morley ${ }^{3}$ \\ M Chantal Hillarby ${ }^{2}$ \\ 'Optometry Department, College of \\ Applied Medical Science, King Saud \\ University, Riyadh, Kingdom of Saudi \\ Arabia; ${ }^{2}$ Division of Pharmacy and \\ Optometry, School of Health Sciences, \\ Faculty of Biology, Medicine and \\ Health, The University of Manchester, \\ ${ }^{3}$ Manchester Royal Eye Hospital, \\ Manchester, UK
}

Purpose: The purpose of this study was to assess UV corneal crosslinking (CXL) treatment outcomes for keratoconus by evaluating the corneal regularity in patients through follow-up using the Oculus Pentacam.

Patients and methods: A total of 18 eyes from CXL patients with keratoconus were studied before and after CXL treatment, and six eyes from six patients who were not treated with CXL served as controls. Treated patients had Pentacam images taken before CXL treatment and regularly 3 months post treatment up to the 12 th month. Controls were imaged during their first appointment and after 12 months. Symmetry and asphericity were evaluated and correlated with both best-corrected visual acuity (BCVA) and maximum $K$-readings.

Results: In the CXL-treated group, there was a significant improvement in the index of symmetrical variation (ISV) and keratoconus index (KI) at 3 months and in the index of height asymmetry (IHA) and minimum radius of curvature $\left(R_{\min }\right)$ at 9 months post treatment. On the contrary, the untreated group's indices showed some significant worsening in ISV, KI, central keratoconus index (CKI), and $R_{\min }$. A novel finding in our study was a slight positive shift of anterior asphericity in the $6 \mathrm{~mm}, 7 \mathrm{~mm}$, and $8 \mathrm{~mm} 3$ months after treatment, which had a correlation with BCVA $\left(R^{2}=0.390, p=0.053\right)$ and a strong correlation with maximum $K$-reading $\left(R^{2}=0.690, p=0.005\right)$. However, the untreated group had no significant changes after 1 year.

Conclusion: The corneal asymmetrical shape is associated with the spherical aberration alteration influenced by temporal evolution of surface ablation and increased corneal haze. However, insignificant changes in symmetry attest the stabilization effect on cornea postoperatively as compared with controls.

Keywords: keratoconus, crosslinking, topography, corneal haze, asphericity

\section{Introduction}

Keratoconus is a bilateral corneal disorder that starts with anterior corneal deterioration and proceeds by affecting the posterior layers. ${ }^{1}$ Onset is usually at puberty and, in many cases, progresses until the third to fourth decade of life. ${ }^{2}$ Asymmetrical corneal thinning, irregular astigmatism, and conical shape reflect an early stage, while a progressive protrusion shows an advanced progression. Krachmer et $\mathrm{al}^{2}$ suggest that keratoconus thinning is central, while others argued that it can also start with the peripheral area. ${ }^{3}$ More recently, keratoconus has been demonstrated to be associated with inflammatory cytokines, especially in the tear film where there is increased proteolytic activity and overexpressed matrix metalloproteinases (MMPs). ${ }^{4}$ Histologically, it is important to understand that the contribution of other stromal cells with the light transmission is essential where keratocytes play a major role to maintain corneal transparency by producing crystalline molecules, which remain in their collagen matrix and decrease scattering. ${ }^{5}$ Therefore, the reduction of basal epithelium density affects
Correspondence: Hanan Mofty

Optometry Department, Office 242,

Third Floor, Building II, College of

Applied Medical Sciences (female section), King Saud University,

Riyadh, Saudi Arabia

Tel+966 I 18055027

Email hmofty@ksu.edu.sa
Clinical Ophthalmology 2017:I I 2043-2049

(c) (1) (8) ๑ 2017 Mofty et al. This work is published and licensed by Dove Medical Press Limited. The full terms of this license are avalable at https:/www.dovepress.com/terms.php cc) hereby accept the Terms. Non-commercial uses of the work are permitted without any further permission from Dove Medical Press Limited, provided the work is properly attributed. For peminsion for commercial use of this work, please see paragraphs 4.2 and 5 of our Terms (https://www. doverperess.com/terms.php). 
the hemidesmosomes and anchoring fibrils with Bowman's layer accompanied by the down growth of epithelial cells. This weakness allows proteolytic enzymes to be released, which may cause instability of Bowman's layer. ${ }^{6}$ As a consequence, stromal collagen lamellae may break down the crosslinks between themselves and grow up to the anterior surface. ${ }^{6}$ However, the posterior stroma in progressive stages is more suspect of increasing the level of corneal hydration and more likely to increase light scatter. ${ }^{5,7}$ In many early cases, both epithelial nuclei and keratocyte nuclei from the anterior stroma appeared, using corneal confocal microscopy, to be in the same plane as Bowman's layer. ${ }^{8}$

Recently, corneal UV crosslinking (CXL) has been established as an effective treatment of keratoconus. ${ }^{9-11}$ This simple technique increases the corneal rigidity and improves the biomechanical properties of the cornea by strengthening the crosslinks between collage lamellae and stabilizes the corneal tissue. ${ }^{12,13}$ In the 1990 s, the first study on photobiology began with attempts to detect the biological glues that could increase the resistance of stromal collage. ${ }^{14}$ A standard approach treating keratoconus was first used in Germany at Dresden Technical University. ${ }^{14}$ Many studies, thereafter, provide an explicit description of the treatments, various procedures, and how it is very necessary to follow specific criteria to prevent any complications. However, these procedures need further investigations to determine if they are adequate to improve corneal rigidity and its biomechanical properties. ${ }^{15}$

For this reason, assessing UV corneal CXL is crucial, especially where CXL treatment has the potential to be an alternative procedure in reducing the progression in forme fruste or preclinical keratoconus. This can be achieved by some new imaging devices that have become more sophisticated by using different imaging principles and techniques. Accordingly, differences in cell density and morphology help contour the corneal layers more accurately. Moreover, the ability of these devices to measure parameters such as thickness, elevation, and biomechanical properties combined with refractive power is used to clarify the disease progression in in vivo cornea as compared to the actual alterations described by laboratory ex vivo studies. ${ }^{16}$ Topographic and tomographic measurements are essential to estimate the capacity of these parameters to assess the treatment effectiveness. This finding confirms the efficacy of corneal biomechanical changes and collagen lamellae organization.

Pachymetry and elevation parameters show high repeatability and reproducibility in several studies ${ }^{16}$ where posterior elevation measurements are more accurate in detecting keratoconus. ${ }^{17}$ Recently, the most common consideration is the accuracy of quantifying surface sphericity, which indicates the maintenance of the corneal structure. ${ }^{18}$ Therefore, descriptors of corneal asymmetry parameters should emphasize and refer to the clinical assessment correctly to classify, monitor, and evaluate the crosslinked cornea. There are many separate elements available in the Oculus Pentacam software for assessing corneal asymmetry. These elements have been found to be more valuable in monitoring the normalization of the cornea. These include the index of symmetrical variation (ISV), keratoconus index (KI), central keratoconus index (CKI), index of height asymmetry (IHA), index of vertical asymmetry (IVA), index of height decentration (IHD), and minimum radius of curvature $\left(R_{\min }\right)$. Previous studies had reported that the cornea becomes more optically regular after CXL using the same indices on patients who were analyzed after 1 year of treatment. ${ }^{19,20}$ However, data from these studies did not assess the posterior corneal elevation changes and peripheral corneal asphericity to show reliable improvement in corneal shape after CXL.

In this study, the corneal asymmetry indices were measured by Oculus Pentacam before and after CXL for keratoconus patients in conjunction with the back elevation (BE) map. Peripheral corneal asphericity (6-8 mm) was also evaluated to to understand the cumulative effect of corneal haze after treatment.

\section{Patients and methods}

This preliminary investigation was a retrospective nonrandomized comparative study. All subjects were recruited from Manchester Royal Eye Hospital (MREH) from August 2015 to August 2016. The study protocol was approved by Central Manchester University Hospital NHS Foundation Trust, Manchester, UK, and Research Ethics Committees in adherence to the guidance of the Declaration of Helsinki. All patients provided informed consent after receiving a detailed description of the nature of the study. A total of 24 eyes from 24 patients were included in this study. The exclusion criteria included patients younger than 18 years or patients with other ocular or systemic disease associated with keratoconus, contact lens wearers, history of eye surgery, scarring, and current topical medication users. Changes in the corneal symmetry in 18 eyes from patients with keratoconus treated with CXL were measured before corneal CXL treatment and 1 month, 3 months, 6 months, and 12 months after treatment. A matched control group of patients with keratoconus who did not have corneal CXL was seen on their first clinical visit and 12 months later. Table 1 summarizes 
Table I Demographic data of both groups, including sample size, age, gender, and Amsler-Krumeich classification of grading keratoconus

\begin{tabular}{lll}
\hline & Treated group & Untreated group \\
\hline Sample size & $\mathrm{n}=18$ & $\mathrm{n}=6$ \\
Age (years) & $26.35 \pm 6.49$ & $29.83 \pm 7.03$ \\
Gender (ratio M:F) & Male I5/female 3 (5:I) & Male 5/female I (5:I) \\
Classification of & $2.063 \pm 0.5$ & $2.15 \pm 0.4$ \\
keratoconus & & \\
\hline
\end{tabular}

Note: Data shown as mean \pm SD and $p$-value.

Abbreviations: SD, standard deviation; $M$, male; F, female.

the demographic data of both groups, including sample size, age, gender, and Amsler-Krumeich classification of grading keratoconus. Patients who underwent corneal CXL treatment were selected from the hospital clinic database. Relevant information including their age, gender, best-corrected visual acuity (BCVA), and date of surgery were recorded for descriptive data analysis. Corneal tomography was evaluated with the Pentacam (OCULUS Optikgeräte Gmbh, Wetzlar, Germany). The diagnosis of keratoconus stages was based on the interpretation of corneal curvature and relative thickness as discussed in the Amsler-Krumeich classification. ${ }^{21}$

Clinical signs such as stromal thinning, corneal steeping, Fleischer ring, Vogt's striae, scissoring reflex, applanation tonometry, dilated funduscopic examination, and abnormal corneal astigmatism were also recorded. Patients following the standard surgical protocol of CXL ( $0.4 \%$ hypotonic riboflavin every $5 \mathrm{~min}$ for $20 \mathrm{~min} /$ ultraviolet-A [UVA; $9.86 \mathrm{~mW}$ ] for $10 \mathrm{~min}$ ) were chosen. Postoperative measurements including corneal tomography and BCVA were also recorded. To minimize the effect of diurnal variation in the corneal swelling, all measurements were performed at the same time between 10:00 and 3:00 PM. Postoperative data of corneal asymmetry indices were retrieved from the Oculus Pentacam database stored in the Oculus Pentacam instrument located in MREH.

\section{Statistical analysis}

Data were analyzed using SPSS 22.0 (IBM Corporation, Armonk, NY, USA). Normality of data was assessed with the Shapiro-Wilk $W$-test. Two groups were analyzed: the untreated keratoconus group and the treated subgroup. Data of the treated group were presented in each follow-up as the mean \pm standard deviation (SD) at baseline, 1-3 months, 4-6 months, 7-9 months, and 10-12 months. The same analysis was performed for the untreated group for two periods of time: first visit and follow-up a year after. A paired two-tailed $t$-test was used to analyze changes in follow-ups as compared to the baseline. An independent $t$-test was used to compare postoperative changes in Pentacam parameters between patients who received corneal CXL and those who did not have CXL after 1 year. Pearson correlation coefficient was used to analyze the possible correlation between BCVA and both asphericity and densitometry. A $p$-value $<0.05$ was used to determine statistical significance.

\section{Results}

A total number of 18 eyes from 18 patients with keratoconus were studied before and after corneal CXL treatment, and an additional six eyes from six patients with keratoconus who were not treated were used as controls. Treated patients were seen throughout their follow-ups at 1-3 months, 4-6 months, 7-9 months, and 10-12 months. For the purpose of analysis, the pre-CXL treatment measurements were considered the baseline. The control group was seen twice: once during their first clinic visit (baseline) and after 1 year.

In the treated group, the initial measurement after CXL shows that central corneal thickness (CCT) has been stabilized as there was no significant change compared to the baseline ( $440.47 \pm 43.22 \mu \mathrm{m}$ to $439.57 \pm 29.68 \mu \mathrm{m}, p=0.313)$. However, the maximum $K$-reading value significantly worsened after 3 months (57.06 $\pm 7.71 \mathrm{D}$ to $54.51 \pm 5.47 \mathrm{D}, p=0.026$ ) and returned with a significant improvement at 9 months $(58.65 \pm 8.77 \mathrm{D}, p=0.035)$. Moreover, BCVA has continuously improved over time, where it showed a significant improvement at 6 months after CXL. However, the untreated group showed a significant progression with a reduction in CCT $(494.83 \pm 46.39 \mu \mathrm{m}$ to $480.50 \pm 46.89 \mu \mathrm{m}, p=0.038)$ and a steeping of the maximum keratometric reading after 1 year. Table 2 shows the initial parameters for both groups at scheduled visits.

In the CXL-treated group, there were significant changes in some of the corneal asymmetry indices such as the ISV and $\mathrm{KI}$ at 3 months after treatment and significant changes in IHA and $R_{\min }$ at 9 months after treatment, but all indices showed no significant changes 1 year after CXL compared with the baseline. However, the control group had significant changes in ISV, KI, CKI, and $R_{\min }$. Surprisingly, maximum posterior elevation (BE) showed continued elevation after 1 year. There were no significant differences between the treated group and the untreated group after 1 year of follow-up in any of the topographic indices.

The mean value of the anterior corneal surface asphericity in the treated group decreased significantly 3 months after treatment in all peripheral rings: $6 \mathrm{~mm}, 7 \mathrm{~mm}$, and $8 \mathrm{~mm}$ ( $p=0.027, p=0.018$, and $p=0.005$, respectively). Conversely, there was a significant negative shift in asphericity 9 months 
Table 2 Comparison of the corneal symmetry indices and asphericity measurement in both treated and untreated group through their scheduled visits

\begin{tabular}{|c|c|c|c|c|c|c|c|}
\hline & \multicolumn{5}{|c|}{ Treated group } & \multicolumn{2}{|c|}{ Untreated group } \\
\hline & $\begin{array}{l}\text { Baseline } \\
(n=18)\end{array}$ & $\begin{array}{l}\text { I-3 months } \\
(n=9)\end{array}$ & $\begin{array}{l}\text { 4-6 months } \\
(n=8)\end{array}$ & $\begin{array}{l}\text { 7-9 months } \\
(n=6)\end{array}$ & $\begin{array}{l}10-12 \text { months } \\
(n=7)\end{array}$ & $\begin{array}{l}\text { Baseline } \\
(n=6)\end{array}$ & $\begin{array}{l}\text { I year follow-up } \\
(n=6)\end{array}$ \\
\hline СCT $(\mu \mathrm{m})$ & $440.47 \pm 43.22$ & $44 I . I I \pm 46.37$ & $436.50 \pm 53.21$ & $440 \pm 48.19$ & $439.57 \pm 29.68$ & $494.83 \pm 46.39$ & $480.50 \pm 46.89$ \\
\hline Maximum K-reading (D) & $57.06 \pm 7.71$ & $54.5 \mathrm{I} \pm 5.47^{*}$ & $60.07 \pm 8.30$ & $58.65 \pm 8.77 *$ & $55.36 \pm 6.05$ & $49.95 \pm 2.25$ & $51.97 \pm 3.83 *$ \\
\hline Minimum K-reading (D) & $52.54 \pm 5.90$ & $50.84 \pm 4.39$ & $55.43 \pm 8.38$ & $53.57 \pm 5.86$ & $51.46 \pm 4.97$ & $47.46 \pm 2.14$ & $49.4 I \pm 4.04 *$ \\
\hline BCVA & $0.39 \pm 0.39$ & $0.4 I \pm 0.23$ & $0.2 I \pm 0.2 I^{*}$ & $0.03 \pm 0.03$ & $0.04 \pm 0.18$ & - & - \\
\hline ISV & $|38.47 \pm 36.7|$ & $126.33 \pm 31.35^{*}$ & I $57.77 \pm 40.44$ & $154.83 \pm 45.78$ & $|2| \pm 30.08$ & $97.16 \pm 29.10$ & $107.83 \pm 31.85 *$ \\
\hline IVA & $1.23 \pm 0.43$ & $1.18 \pm 0.19$ & $1.32 \pm 0.38$ & $1.26 \pm 0.39$ & $1.05 \pm 0.314$ & $1.05 \pm 0.43$ & $1.07 \pm 0.4 \mathrm{I}$ \\
\hline $\mathrm{KI}$ & $1.37 \pm 0.12$ & $1.35 \pm 0.13 *$ & $1.44 \pm 0.14$ & $1.37 \pm 0.15$ & $1.32 \pm 0.14$ & $1.25 \pm 0.12$ & $1.29 \pm 0.13^{*}$ \\
\hline CKI & $1.16 \pm 0.09$ & $1.13 \pm 0.05$ & $1.20 \pm 0.10$ & $1.23 \pm 0.10 *$ & $1.15 \pm 0.06$ & $1.09 \pm 0.03$ & $1.12 \pm 0.05^{*}$ \\
\hline IHA & $52.69 \pm 35.21$ & $42.87 \pm 37.22$ & $39.95 \pm 35.25$ & $18.46 \pm 12.30 *$ & $42.51 \pm 16.99$ & $34.75 \pm 22.05$ & $25.30 \pm 16.19$ \\
\hline IHD & $0.22 \pm 0.07$ & $0.18 \pm 0.05$ & $0.24 \pm 0.07$ & $0.22 \pm 0.08$ & $0.19 \pm 0.06$ & $0.16 \pm 0.06$ & $0.17 \pm 0.06$ \\
\hline$R_{\min }(\mathrm{mm})$ & $5.14 \pm 0.7 \mid$ & $5.36 \pm 0.56$ & $4.83 \pm 0.73$ & $4.82 \pm 0.86^{*}$ & $5.26 \pm 0.67$ & $5.80 \pm 0.54$ & $5.55 \pm 0.7 I^{*}$ \\
\hline BFS (mm) & $5.89 \pm 0.32$ & $6.00 \pm 0.22$ & $5.80 \pm 0.32$ & $5.90 \pm 0.31$ & $5.96 \pm 0.11$ & $6.13 \pm 0.26$ & $6.05 \pm 0.29$ \\
\hline $\mathrm{BE}(\mathrm{mm})$ & $69.70 \pm 35.10$ & $61.44 \pm 29.97$ & $83.00 \pm 43.37$ & $87.66 \pm 39.98$ & $88.28 \pm 31.32 *$ & $40.17 \pm 15.30$ & $52.17 \pm 24.54 *$ \\
\hline Asphericity $6 \mathrm{~mm}$ ( $Q$-value) & $-1.91 \pm 0.85$ & $-1.78 \pm 0.74 *$ & $-2.30 \pm 0.94$ & $-2.52 \pm 0.96^{*}$ & $-1.86 \pm 0.63 *$ & $-1.13 \pm 0.45$ & $-1.45 \pm 0.67$ \\
\hline Asphericity $7 \mathrm{~mm}$ ( $Q$-value) & $-1.68 \pm 0.76$ & $-1.58 \pm 0.66 *$ & $-2.06 \pm 0.86$ & $-2.16 \pm 0.87$ & $-1.61 \pm 0.55^{*}$ & $-1.05 \pm 0.38$ & $-1.36 \pm 0.53$ \\
\hline Asphericity $8 \mathrm{~mm}$ ( $Q$-value) & $-1.50 \pm 0.65$ & $-1.40 \pm 0.56 *$ & $-1.82 \pm 0.79$ & $-1.87 \pm 0.77$ & $-1.43 \pm 0.47$ & $-0.87 \pm 0.32$ & $-1.10 \pm 0.44$ \\
\hline
\end{tabular}

Notes: *Statistically significant compared to baseline $(p<0.05)$. Data presented as mean \pm SD and $p$-value.

Abbreviations: SD, standard deviation; CCT, central corneal thickness; BCVA, best-corrected visual acuity; ISV, index of symmetrical variation; IVA, index of vertical asymmetry; KI, keratoconus index; CKI, central keratoconus index; IHA, index of height asymmetry; IHD, index of height decentration; $R_{\text {min }}$, minimum radius of curvature; $\mathrm{BFS}$, best-fit sphere; $\mathrm{BE}$, back elevation; $Q$-value, anterior corneal asphericity.

after surgery in all peripheral rings $(6 \mathrm{~mm}, 7 \mathrm{~mm}$, and $8 \mathrm{~mm})$, where it was only significant in the $6 \mathrm{~mm}$ ring with $p=0.048$. After that, all peripheral rings turned with a positive shift 1 year postoperatively $(p=0.031, p=0.047$, and $p=0.105)$ as shown in Figure 1. The untreated group showed no significant changes after 1 year of follow-up, although there was a slight increase in their measurements. Moreover, there were no significant differences between the treated group and the

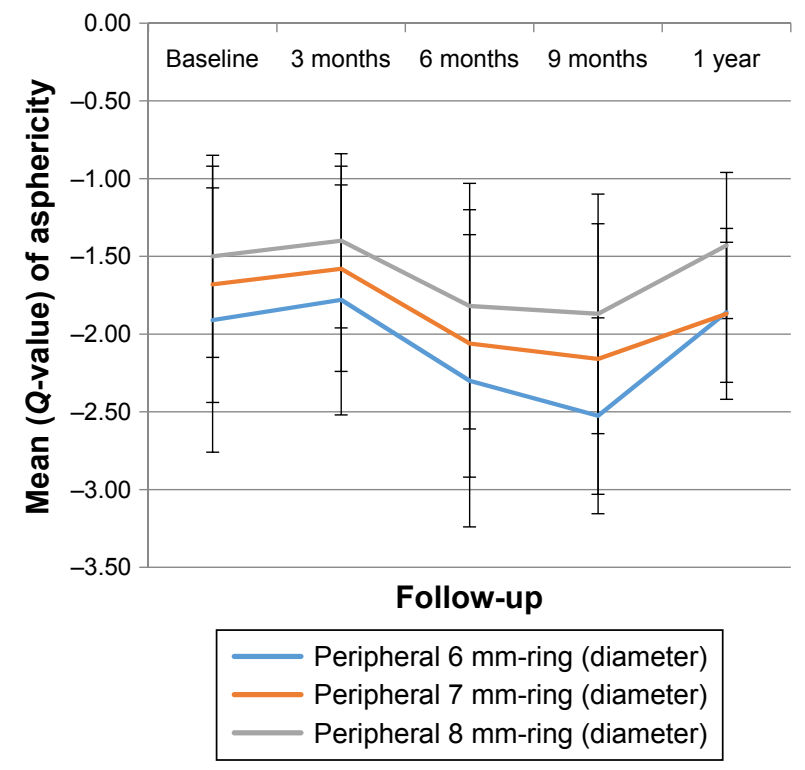

Figure I Changes in the anterior corneal surface asphericity over time in the treated group. untreated group in the mean value after 1 year of follow-up in all topographic indices $(p>0.05)$.

Within the CXL group, the absolute measurement of the peripheral $6 \mathrm{~mm}$ ring of the anterior corneal asphericity at 3 months indicates an insignificant negative correlation with BCVA $\left(R^{2}=0.390, p=0.053\right)$, but maximum $K$-reading shows a strong negative correlation with all zones at 3 months (6 mm: $R^{2}=0.704, p=0.005 ; 7 \mathrm{~mm}: R^{2}=0.676, p=0.007 ; 8 \mathrm{~mm}$ : $R^{2}=0.682, p=0.006$; Figures 2 and 3 ). However, both show no correlation with asphericity changes at 6 months, 9 months, and 12 months after treatment in all peripheral rings.

\section{Discussion}

Collagen CXL treatment is widely used for keratoconus patients to improve corneal rigidity and visual outcome. According to the significant improvement in distance vision and evidential ability to stabilize progression of this disease, this treatment has been used in many cases as a first-line treatment option for early keratoconus stages. On the other hand, the alteration in the stromal histological structure induces a postoperative visual acuity reduction within the first few months after treatment. Moreover, the collagen fibers will vary in their diameter and regularity, which increase light scatters and affect corneal transparency. As a consequence, continuous corneal haze symptoms have been observed in most cases after CXL. ${ }^{22}$

The first part of this study demonstrates evaluating tissue disturbances by measuring corneal symmetry, which 

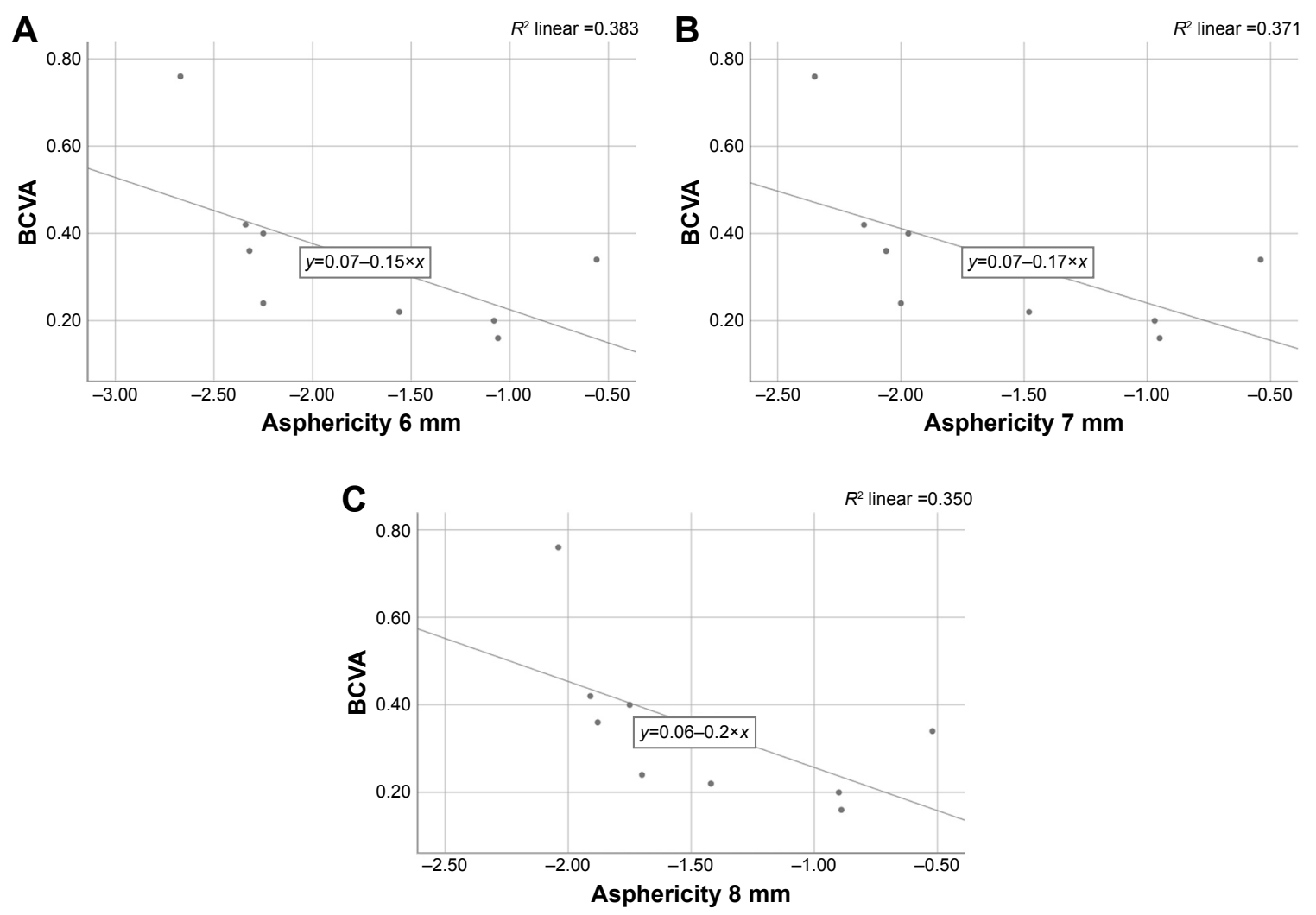

Figure 2 Correlation between BCVA and asphericity at 3 months in (A) in $6 \mathrm{~mm}$ ring, (B) in $7 \mathrm{~mm}$ ring and (C) in $8 \mathrm{~mm}$ ring. Abbreviation: BCVA, best-corrected visual acuity.
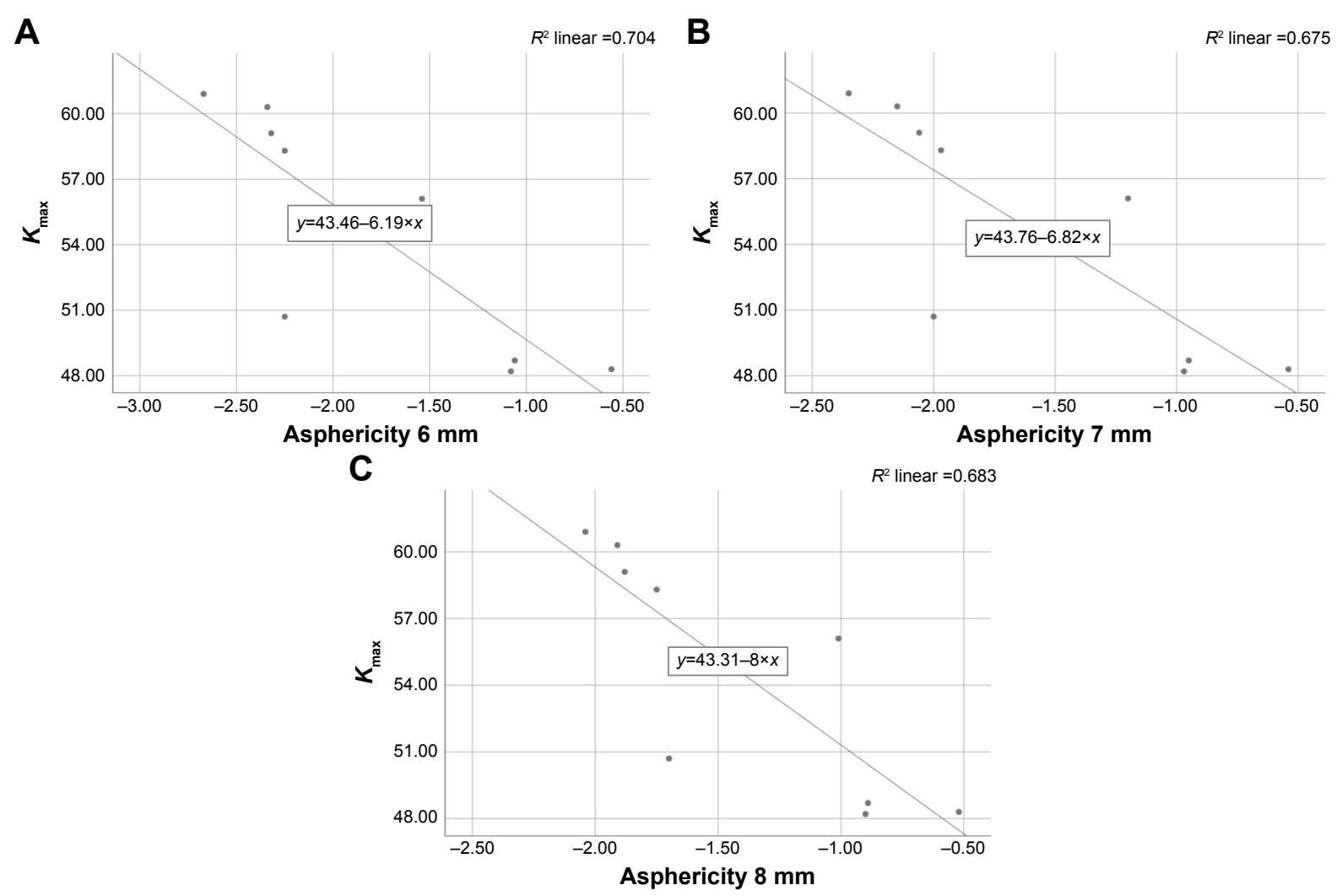

Figure 3 Correlation between $K_{\max }$ and asphericity at 3 months in (A) in $6 \mathrm{~mm}$ ring, (B) in $7 \mathrm{~mm}$ ring and (C) in $8 \mathrm{~mm}$ ring. Abbreviation: $K_{\max }$, maximum $K$-reading. 
indicates the recovery of corneal asymmetrical shape and the reduction in the biomechanical deformation. The Oculus Pentacam software provides abnormal values in topographic measurement of symmetrical indices in keratoconus. Therefore, these parameters may be useful in following the progressive changes in keratoconus patients and increase our comprehension of the restoration of the corneal shape after CXL treatment.

Our finding for the treated group shows a significant reduction in the ISV and KI after 3 months and a significant reduction in IHA and $R_{\min } 9$ months after treatment, whereas other indices show no significant changes. Based on this finding, we suggested that the cornea has been flattened as a result of CXL treatment.

To our knowledge, the study of Gutiérrez et $\mathrm{al}^{23}$ is the only study measuring index changes over time and, in contrast to our results, found a significant reduction in the IVA and the IHA at 3 months $(p<0.05)$ which returned to baseline values after 6 months.

Our study also showed that there were no significant changes in all indices 1 year after treatment, and this finding has good agreement with the studies of Gutiérrez et al and Razmjoo et al. In contrary to our findings, Toprak et al reported an improvement in the corneal regularity by significant reduction in ISV, CKI, and $R_{\min }$. In their study, patients were treated with isotonic riboflavin solution and the baseline of maximum $K$-reading value was lower than that of our treated group $(53.83 \pm 64.43 \mathrm{D}) .^{19,23,24}$

Koller et al also found significant improvements in CKI, $R_{\text {min }}, \mathrm{KI}$, and IHA indices 1 year after CXL in patients with progressive keratectasia. However, their crosslinked group had an average corneal thickness of $456 \mu \mathrm{m}$, while in our study, the group has been treated with further reduction in CCT of $440 \mu \mathrm{m}$. This may reflect that both Toprak et al and Koller et al treated their patients in earlier stages of keratoconus than in our patients. Changes in the refractive index of the crosslinked stromal layer also might be an explanation leading to a false thinner result of optical ray tracing. ${ }^{20}$

Moreover, we have detected changes in some indices in the untreated group where ISV, KI, CKI, and $R_{\text {min }}$ were significantly progressed, which was similar to the control group of Koller et al. This finding supports the idea of the effectiveness of CXL in declining progression and enhancing corneal regularity in the treated group.

Surprisingly, we have found a significant continuous progression of the posterior cornea after 1 year in both groups. The same trend was seen in the study of Gutiérrez et al, although insignificant changes were observed. Our assumption of this continuous elevation is related to intrastromal shrinking processes of the anterior part of chemical bonds induced by the radicals formed during CXL, causing a secondary distortion of the posterior layers. ${ }^{20}$

A novel finding in our study was a significant positive shift of anterior corneal asphericity in the $6 \mathrm{~mm}, 7 \mathrm{~mm}$, and $8 \mathrm{~mm}$ peripheral rings 3 months after treatment. This has a weak correlation with visual acuity reduction $\left(R^{2}=0.390, p=0.053\right)$ but a strong correlation with the maximum $K$-reading $\left(R^{2}=0.704\right.$, $p=0.005$ ). This change might be explained by pointing out that the cause of spherical aberration is influenced by the alteration in the corneal curvature. Subsequent measurements resulted in a significant negative direction after 6 months, which may be due to the temporal evolution of surface ablation. At 12 months, there was another significant positive change in asphericity in the $6 \mathrm{~mm}$ ring diameter, while there were no changes verified at $7 \mathrm{~mm}$ and $8 \mathrm{~mm}$. This finding is similar to the finding of Koller et al where they reported that $Q_{\text {ant }}$ was calculated within a circular area of $8 \mathrm{~mm}$. As compared to the treated group, the untreated group showed an insignificant negative shift at the 1 year follow-up. This finding contrasted to that of Kovács et al where they reported on those who had relevant negative posterior $Q$-values because of corneal protrusion. However, they used a different way of measuring asphericity by measuring $Q$-value at the sagittal angle ring at $30^{\circ}$ centered on the apex, which showed high accuracy $(90 \%$ of specificity) and moderate sensitivity $(60 \%) .{ }^{25}$ This difference could be attributed to the size of our untreated group, which was too small as compared to their study. The limitation of this study was because of a small sample size which had some impact on the statistical results due to a small number of non-contact lens wearers in this stage of keratoconus. Another problem was the loss of patients during their follow-up, which is an important factor in the strength of our conclusions about each period. For instance, for precise results, the same methodology in previous studies was chosen for our research and measurements were taken after a 3-month period of time subsequently. ${ }^{23}$ However, due to the high demand and overloading of hospital appointments, there may have been inability of patients to visit clinics at a required time. Moreover, extending and expanding follow-up assessment are required to understand the nature of the corneal haze. In doing so, finding a correlation between corneal shape objectively and contrast sensitivity subjectively after treatment is helpful to investigate the relationship between visual improvement, spherical aberration reduction, and haze discomfort. ${ }^{26}$

\section{Conclusion}

This study reveals the impact of CXL treatment in corneal symmetrical indices and asphericity measurements during 
consecutive periods of follow-ups. The strong correlation between asphericity and keratometric reading 3 months after CXL treatment reflects the tissue disturbance influenced by the temporal ablation of the cornea. This contributes to some complaints such as visual reduction and the corneal haze. Interestingly, our study shows insignificant asymmetrical alteration in the corneal shape 1 year after treatment, which explains the structural constancy and confirms the tissue recovery. This also emphasizes the aspect that these objective measurements are able to interpret the progression of keratoconus.

\section{Acknowledgment}

The abstract was presented at the 10th International Conference on Clinical \& Experimental Ophthalmology, November 21-23, 2016, Dubai, UAE, and at the Association for Research in Vision and Ophthalmology (ARVO), May 7-11, 2017, USA.

The first author would like to thank her parents for their constant support, and Dr Amal Al-Darweesh for her helpful advice to write this paper.

\section{Disclosure}

The authors report no conflicts of interest in this work.

\section{References}

1. Mathew JH, Goosey JD, Bergmanson JP. Quantified histopathology of the keratoconic cornea. Optom Vis Sci. 2011;88(8):988-997.

2. Krachmer JH, Feder RS, Belin MW. Keratoconus and related noninflammatory corneal thinning disorders. Surv Ophthalmol. 1984;28(4): 293-322.

3. Brautaset RL, Nilsson M, Miller WL, Leach NE, Tukler JH, Bergmanson JP. Central and peripheral corneal thinning in keratoconus. Cornea. 2013;32(3):257-261.

4. Balasubramanian SA, Mohan S, Pye DC, Willcox MDP. Proteases, proteolysis and inflammatory molecules in the tears of people with keratoconus. Acta Ophthalmol. 2012;90(4):e303-e309.

5. Gardner SJ, White N, Albon J, Knupp C, Kamma-Lorger CS, Meek KM. Measuring the refractive index of bovine corneal stromal cells using quantitative phase imaging. Biophys J. 2015;109(8):1592-1599.

6. Rabinowitz YS. Keratoconus. Surv Ophthalmol. 1998;42(4):297-319.

7. Meek KM, Leonard DW, Connon CJ, Dennis S, Khan S. Transparency, swelling and scarring in the corneal stroma. Eye. 2003;17(8):927.

8. Efron N, Hollingsworth JG. New perspectives on keratoconus as revealed by corneal confocal microscopy. Clin Exp Optom. 2008;91(1): 34-55.

9. Raiskup-Wolf F, Hoyer A, Spoerl E, Pillunat LE. Collagen crosslinking with riboflavin and ultraviolet-A light in keratoconus: long-term results. J Cataract Refract Surg. 2008;34(5):796-801.

Clinical Ophthalmology

\section{Publish your work in this journal}

Clinical Ophthalmology is an international, peer-reviewed journal covering all subspecialties within ophthalmology. Key topics include: Optometry; Visual science; Pharmacology and drug therapy in eye diseases; Basic Sciences; Primary and Secondary eye care; Patient Safety and Quality of Care Improvements. This journal is indexed on Submit your manuscript here: http://www.dovepress.com/clinical-ophthalmology-journal
10. Caruso C, Ostacolo C, Epstein RL, Barbaro G, Troisi S, Capobianco D. Transepithelial corneal cross-linking with vitamin E-enhanced riboflavin solution and abbreviated, low-dose UV-A: 24-month clinical outcomes. Cornea. 2016;35(2):145-150.

11. Mazzotta C, Moramarco A, Traversi C, Baiocchi S, Iovieno A, Fontana L. Accelerated corneal collagen cross-linking using topography-guided UV-A energy emission: preliminary clinical and morphological outcomes. J Ophthalmol. 2016;2016:2031031.

12. Padmanabhan P, Radhakrishnan A, Venkataraman AP, Gupta N, Srinivasan B. Corneal changes following collagen cross linking and simultaneous topography guided photoablation with collagen cross linking for keratoconus. Indian J Ophthalmol. 2014;62(2):229-235.

13. Shetty R, Nuijts RM, Srivatsa P, et al. Understanding the correlation between tomographic and biomechanical severity of keratoconic corneas. Biomed Res Int. 2015;2015:294197.

14. Wollensak G, Spoerl E, Seiler T. Riboflavin/ultraviolet-a-induced collagen crosslinking for the treatment of keratoconus. Am J Ophthalmol. 2003;135(5):620-627.

15. Vellara HR, Patel DV. Biomechanical properties of the keratoconic cornea: a review. Clin Exp Optom. 2015;98(1):31-38.

16. de Sanctis U, Missolungi A, Mutani B, Richiardi L, Grignolo FM. Reproducibility and repeatability of central corneal thickness measurement in keratoconus using the rotating Scheimpflug camera and ultrasound pachymetry. Am J Ophthalmol. 2007;144(5):712-718.

17. de Sanctis U, Loiacono C, Richiardi L, Turco D, Mutani B, Grignolo FM. Sensitivity and specificity of posterior corneal elevation measured by Pentacam in discriminating keratoconus/subclinical keratoconus. Ophthalmology. 2008;115(9):1534-1539.

18. Mas-Aixala E, Gispets J, Lupón N, Cardona G. The variability of corneal and anterior segment parameters in keratoconus. Cont Lens Anterior Eye. 2016;39(6):466-470.

19. Toprak I, Yildirim C. Effects of corneal collagen crosslinking on corneal topographic indices in patients with keratoconus. Eye Contact Lens. 2013;39(6):385-387.

20. Koller T, Iseli HP, Hafezi F, Vinciguerra P, Seiler T. Scheimpflug imaging of corneas after collagen cross-linking. Cornea. 2009;28(5): $510-515$.

21. Amsler M. Keratocone classique et keratocone fruste; arguments unitaires. Ophthalmologica. 1946;111(2-3):96-101.

22. Koller T, Schumacher S, Franz Fankhauser II, Seiler T. Riboflavin/ ultraviolet a crosslinking of the paracentral cornea. Cornea. 2013;32(2): $165-168$.

23. Gutiérrez R, Lopez I, Villa-Collar C, González-Méijome JM. Corneal transparency after cross-linking for keratoconus: 1-year follow-up. J Refract Surg. 2012;28(11):781-786.

24. Razmjoo H, Nasrollahi AP, Salam H, Karbasi N, Najarzadegan MR. Topographic corneal changes after collagen cross-linking in patients with corneal keratoconus. J Res Med Sci. 2013;18(10):882-886.

25. Kovács I, Miháltz K, Ecsedy M, Németh J, Nagy ZZ. The role of reference body selection in calculating posterior corneal elevation and prediction of keratoconus using rotating Scheimpflug camera. Acta Ophthalmol. 2011;89(3):e251-e256.

26. Zarei-Ghanavati S, Khakshour H, Vejdani M, Ghooshkhanei H, Vejdani A. Evaluation of changes in visual acuity, contrast sensitivity and aberrations in patients with keratoconus after corneal collagen cross-linking. J Ophthalmic Vis Res. 2017;12(3):260.

\section{Dovepress}

PubMed Central and CAS, and is the official journal of The Society of Clinical Ophthalmology (SCO). The manuscript management system is completely online and includes a very quick and fair peer-review system, which is all easy to use. Visit http://www.dovepress.com/ testimonials.php to read real quotes from published authors. 